\title{
Studies on Mechanical and Wear Properties of Al6061/Beryl Composites
}

\author{
Hosur Nanjireddy Reddappa ${ }^{1 *}$, Kitakanur Ramareddy Suresh ${ }^{1}$, Hollakere Basavaraj Niranjan ${ }^{2}$, \\ Kestur Gundappa Satyanarayana ${ }^{3}$ \\ ${ }^{1}$ Department of Industrial Engineering \& Management, Bangalore Institute of Technology, Bangalore, India \\ ${ }^{2} \mathrm{HKBK}$ College of Engineering, Bangalore, India \\ ${ }^{3}$ Research \& Development Centre, BMS College of Engineering, Bangalore, India \\ Email: *reddyhn.phd@gmail.com
}

Received March 25, 2012; revised May 10, 2012; accepted June 1, 2012

\begin{abstract}
Beryl-Al6061 alloy composites having $2-12 \mathrm{wt} \%$ of beryl particles were fabricated by liquid metallurgy (stir cast) method. The tensile and wear properties of beryl-Al6061 composites have been evaluated and compared with its base alloy. The results revealed that the Al6061-10 wt $\%$ of beryl composites shows an improvement of $15.38 \%$ in tensile strength and specific wear rate decreases by $8.9 \%$ at normal load of $9.81 \mathrm{~N}$ when compared to matrix i.e. base alloy. Significant improvement in tensile properties and hardness are noticed as the $\mathrm{wt} \%$ of the beryl particles increases. The microstructures of the composites were studied to know the uniform dispersion of the beryl particles in matrix. It has been observed that addition of beryl particles significantly improves ultimate tensile strength and hardness properties as compared with that of unreinforced matrix.
\end{abstract}

Keywords: Tensile Strength; Hardness; Wear; A16061; Beryl

\section{Introduction}

The aluminium alloys reinforced with ceramic particles emerged as a new generation of engineering materials with improved mechanical properties to weight ratio $[1,2]$. Aluminium matrix composites offer good mechanical and superior wear resistance properties when compared to the alloy irrespective of applied load and sliding speed. This is primarily due to the fact that the hard particles like $\mathrm{SiC}$, WC and $\mathrm{Al}_{2} \mathrm{O}_{3}$ etc., when dispersoid in matrix which makes the matrix alloy plastically constrained and improves the high temperature strength of the base alloy [3].

Most of the researchers have investigated aluminium composites by different processing routes [4]. Of all the processing routes, liquid metallurgy method is the most sought after owing to its several advantages such as economical, mass production, near net shaped components can be produced [5]. Hosking et al. reported in their research work Al2024 alloy with $20 \mathrm{wt} \%$ of alumina shows good wear resistance [6]. Wang and Rack reported that although the wear rate of Al7091 alloy and Al7091-SiC composites are almost the same at a sliding velocity of $1.2 \mathrm{~m} / \mathrm{s}$, but with increase in increasing sliding velocity composites exhibit lower wear rate than that of unreinforced matrix [7]. The abrasive wear rate of A16061-

"Corresponding author. alumina fiber composites was found to be much less, indicating almost six times better wear resistance than matrix alloy [8]. Use of $\mathrm{TiO}_{2}$ as reinforcement in aluminum alloys has received little attention although it possess high hardness and modulus with superior corrosion resistance [4]. Of all the aluminum alloys, Al6061 is quite popular choice as a matrix material to prepare metal matrix composites owing to its better formability characteristics and option of modification of the strength of composites by adopting optimal heat treatment [9].

In recent years, aluminum alloy based metal matrix composites (MMCs) are being explored as candidate materials in several interesting applications such as piston, connecting rod, contactors, where sliding is a key component [4]. Excessive wear, due to sliding, will ultimately result in seizure of the mating parts sometimes leading to catastrophic failure [10]. Hence, prediction of the wear behaviour of the sliding components is of utmost importance avoiding huge economic losses. Tribological characteristics of several MMC systems involving glass, flash, $\mathrm{SiC}$, graphite, mica, $\mathrm{Al}_{2} \mathrm{O}_{3}$ as discontinuous dispersoids have been reported [11-13]. Berylsilicate of aluminum and beryllium is one of the naturally available mineral. As observed in various literatures, the particle reinforced Aluminum composites shows reasonably good wear resistance. However, there is very 
little work is reported with "beryl" being used as a reinforcing phase in aluminum matrix. Hence the aims of the study are: 1) To standardize the beryl addition to liquid aluminum alloy; 2) To examine the mechanical and wear properties of these aluminum matrix composites.

\section{Material and Experimental Procedures}

\subsection{Matrix Material}

The matrix chosen for this work is ASM 6061 Al-Mg-Si alloy. It has the highest strength and ductility of the aluminium alloys with excellent machinability and good bearing and wear properties [14].

\subsection{Reinforcing Materials}

Beryl, a naturally occurring mineral having the formula $\left(\mathrm{Be}_{3} \mathrm{Al}_{2}\left(\mathrm{SiO}_{3}\right)_{6}\right)$ was used as the reinforcing material, while Al6061 alloy has been used as the matrix. The beryl particles used were of $45-60 \mu \mathrm{m}$ size. They have a density of $2.6-2.8 \mathrm{~g} / \mathrm{mm}^{3}$ which is almost on par with that of Al6061 and has hardness of 7.5 to 8 on Mho's scale and a hexagonal structure $[15,16]$. The chemical composition of beryl particles are shown in the Table 1.

A liquid metallurgy route has been adopted to prepare the cast composites as described in our earlier works [9]. Al6061 has been chosen as the matrix alloy. Preheated beryl particle of size 53 - $75 \mu \mathrm{m}$ was introduced into the vortex of the molten alloy after effective degassing. Mechanical stirring of the molten alloy for duration of 10 min was achieved by using ceramic-coated steel impeller with a speed of $300 \mathrm{rpm}$ was maintained. A pouring temperature of $710^{\circ} \mathrm{C}$ was adopted and the molten composite was poured into cast iron moulds. The extent of incorporation of beryl in the matrix alloy was varied from 2 to $12 \mathrm{wt} \%$.

The cast composites and matrix were machined to obtain tensile, hardness and wear specimens; the tensile test was carried out on samples according to ASTM-E8. All the composites were tested for strength, samples were loaded till fracture. Three trials were carried out for the purpose of repeatability and the average of them is presented here. Hardness has some influence on the wear behavior on any material. Hence, the hardness was measured for the composite samples as well as squeeze cast alloy. The hardness tests were carried out as per ASTM-E-10-93 standard. The tests were conducted on three locations on the sample to counter the possibility of indenter resting on hard particle, which may result in anomalous value.
Wear tests were carried out using a pin-on-disc apparatus (MODEL:TR20-LE, WEAR AND FRICTION MONITOR, DUCOM MAKE, INDIA) as per ASTMG99-95 standard under varying applied pressure and sliding distance at a fixed sliding speed of $1.66 \mathrm{~m} / \mathrm{s}$. against an EN32 steel disc. The specimen samples were 8 $\mathrm{mm}$ diameter and $25 \mathrm{~mm}$ length. The surface of the specimen sample and the steel disc were ground using emery paper (grit size: 240 ) prior to each test. The samples were cleaned with acetone. The wear losses of sample specimens were measured as height loss in microns which was recorded using an LVDT transducer of accuracy of $1 \mu \mathrm{m}$. The measurement of wear loss of the specimen was used to evaluate the volumetric loss, which in turn was used to compute the specific wear rate of the composites. Lastly, wear surface were studied with SEM to determine the wear mechanism undergone by the material.

\section{Results and Discussions}

\subsection{Morphology}

The microstructure of Al6061 and Al6061-10 wt\% of beryl composite are shown in Figures 1(a) and (b). The microstructure clearly indicates fairly uniform distribution of beryl particles in the matrix along with evidence of minimal porosity in both the base alloy and the composite. Further, an excellent bonding between the matrix and the reinforcement particles was observed.

\subsection{Tensile Strength}

The properties of composites samples reinforced with "beryl" particles were evaluated and compared with that of matrix material, to see the effect of addition of particles. The results are reported below. The addition of beryl particles enhances the tensile strength of the base material as can be seen from Figure 2. However, peak tensile strength is for an addition of $10 \%$ by weight of particles.

The presence of hard beryl particles may be responsible for the improvement in strength. Theses particles impede the advancing dislocation front [17-21]. The addition of these particles may have given rise to large residual compressive stress developed during solidification due to difference in coefficient of expansion between ductile matrix and brittle ceramic particles [22-26]. The enhancement in strength may also be attributed to closer packing of reinforcement and hence small interparticle spacing in the matrix, at the same time it may be due to

Table 1. Chemical composition of beryl particles.

\begin{tabular}{cccccccccc}
\hline Element & $\mathrm{SiO}_{2}$ & $\mathrm{Al}_{2} \mathrm{O}_{3}$ & $\mathrm{BeO}$ & $\mathrm{Fe}_{2} \mathrm{O}_{3}$ & $\mathrm{CaO}$ & $\mathrm{MgO}$ & $\mathrm{Na}_{2} \mathrm{O}$ & $\mathrm{K}_{2} \mathrm{O}$ & $\mathrm{MnO}$ \\
\hline Composition (\%) & 65.4 & 17.9 & 12.3 & 0.8 & 1.34 & 0.48 & 0.55 & 0.004 & 0.05 \\
\hline
\end{tabular}




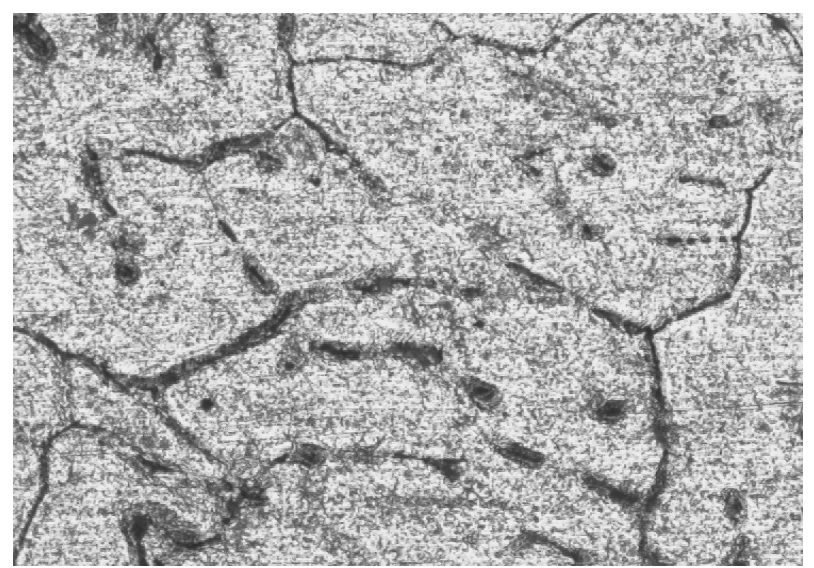

(a)

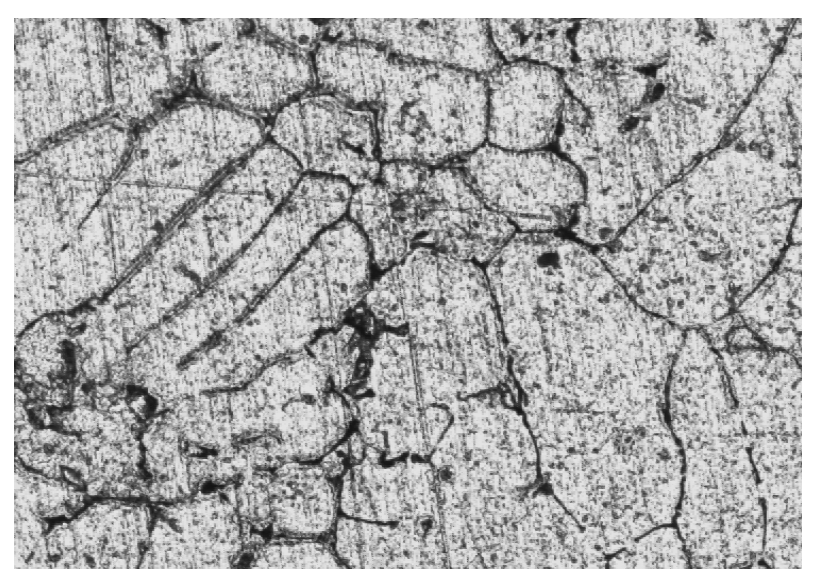

(b)

Figure 1. Microstructure of (a) Al6061 (200×); (b) Al6061$10 \%$ beryl composite $(200 \times)$.

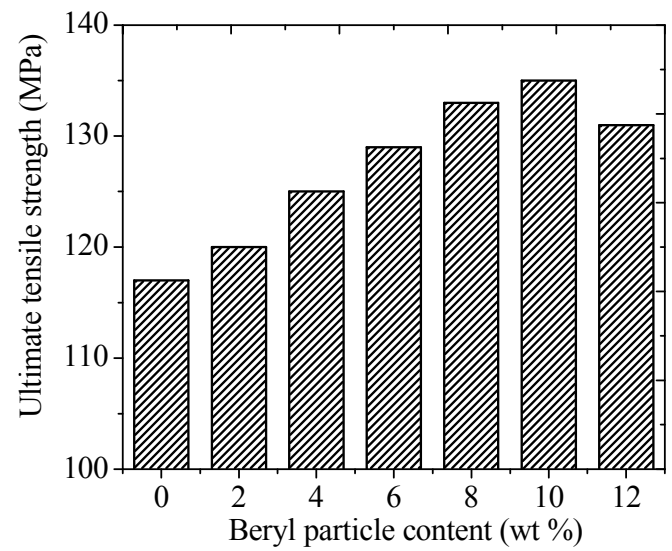

Figure 2. Ultimate Tensile Strength (UTS) of Al6061/beryl composites.

composite's ability to exhibit internal ductility to redistribute high localized internal stresses [27].

\subsection{Hardness}

The dispersion of beryl particles enhances the hardness of the matrix, since beryl particles being harder than aluminum alloy, render additional hardness to the matrix [28]. The hardness shows a linear relationship with the quantity of particle addition. The composite with $12 \%$ weight particle has hardness, enhanced nearly by $36.64 \%$ when compared to the base alloy (Figure 3).

\subsection{Dry Sliding Wear}

The specific wear rate of test specimens in $\mathrm{mm}^{3} / \mathrm{N}-\mathrm{m}$ obtained from the height loss of the specimens during sliding is plotted against sliding distance for a applied load of $9.81 \mathrm{~N}$. The specific wear rates of unreinforced alloy and six different composite specimens with varying volume percentage of particle reinforcement ( $2 \%$ to $12 \%$ ) are shown in Figure 4.

It may seen from the Figure $\mathbf{4}$ that for any given wear sliding distance the increased addition of beryl particles results in a decrease in the specific wear rate of the specimen. This inverse relationship may be directly related to the improvement in the hardness of the composites as the amount of beryl is raised.

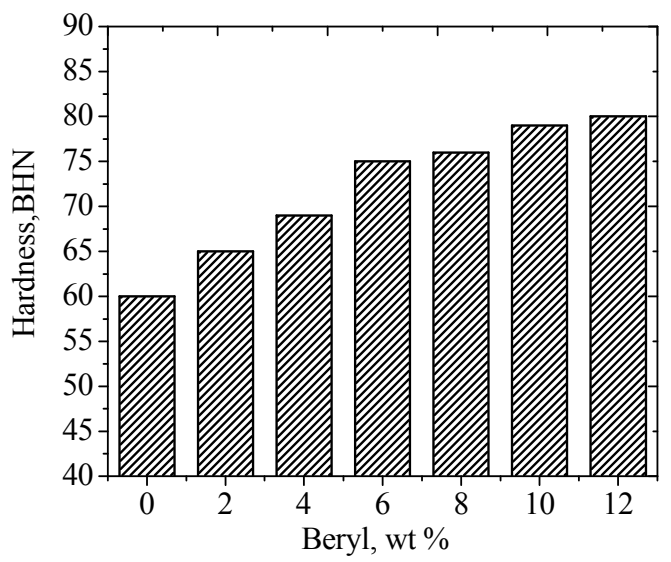

Figure 3. Variation of hardness of Al6061/beryl composites with increased content of beryl.

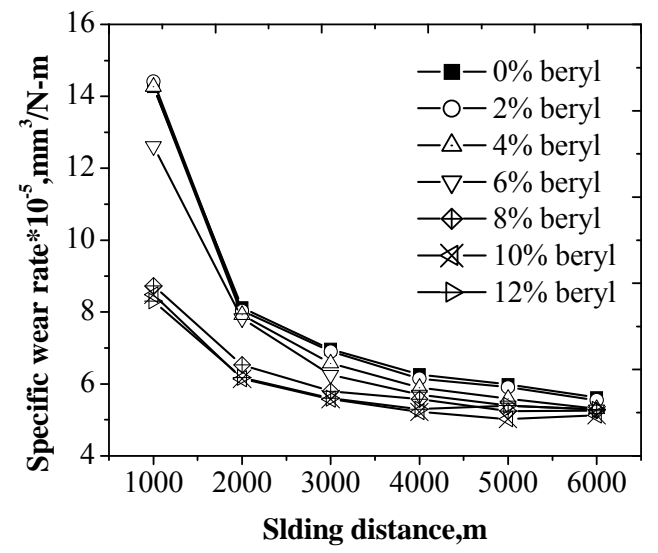

Figure 4. Specific wear rate (Sliding speed: $1.66 \mathrm{~m} / \mathrm{s}$, Load: $9.81 \mathrm{~N}$ ) for different sliding distances. 


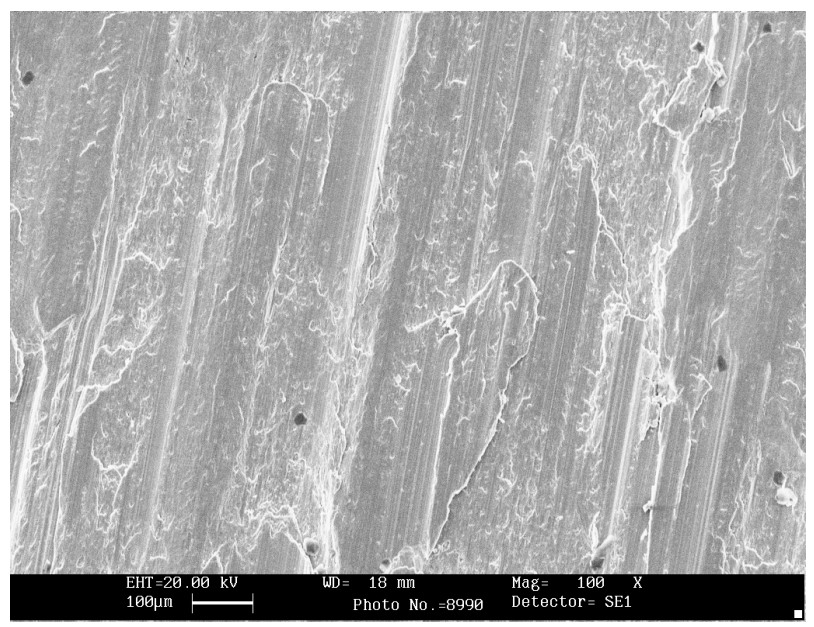

(a)

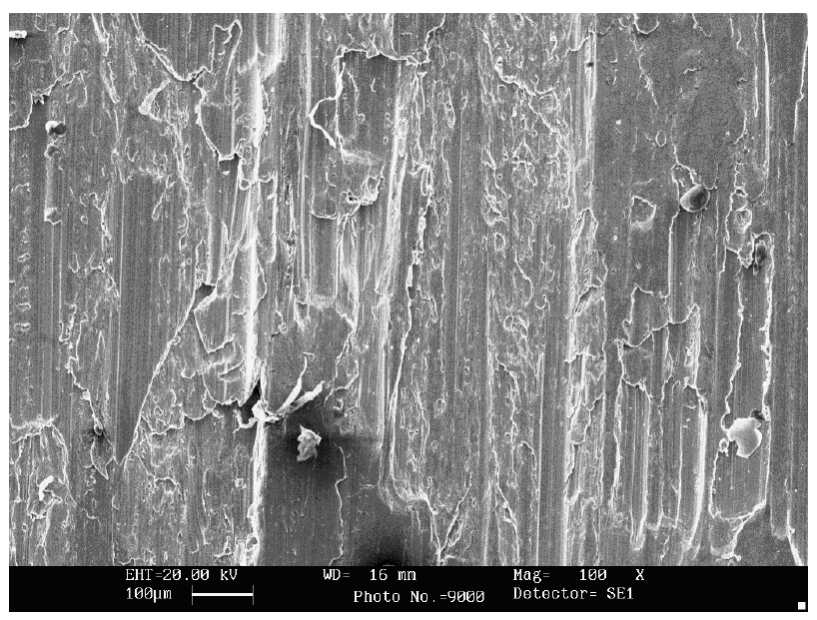

(b)

Figure 5. Worn surface of (a) Al6061 alloy; (b) Al6061-10\% beryl composite (Load: $9.81 \mathrm{~N}$, Sliding speed: $1.66 \mathrm{~m} / \mathrm{s}$ ).

The specific wear rate of beryl reinforced composites decreases with increase in beryl content in the dry-sliding wear tests. The asperities of both the pin and counter face which were in contact with each other were subjected to relative motion under the influence of sliding distance. Initially, both the surfaces are associated with a large number of sharp asperities and contact between the two surfaces takes place primarily at these points.

In the present case, a number of reinforcements were observed on the asperities on the pin. Under the influence of increased sliding distances, the asperities in each surface came in contact with each other and they were either plastically deformed or remained in elastic contact. As the asperities were very sharp in nature, the effective stress on these sharp points might have been more than the elastic stress and then all these sharp asperities were plastically deformed at their contact points except the plastically projected points of the reinforcement due to a moderate increase in temperature of contact surface. This is because of continuous sliding motion for a longer du- ration on increased distance. The plastically deformed surface would then fill the valley of the material both in specimen and disc surface during the course of action and there was a possibility of fracture a few asperities on both the surfaces leading to very fine debris [29].

The Figures 5(a) and (b) depicts the worn worn surfaces of both matrix-A16061 alloy and A16061-10\% beryl composite. The examination of the worn surfaces shows that the composite exhibited generally much rougher surface than that of the Al6061 alloy. In the case of composite, cavities and large grooved regions were observed on the worn surface. The fact that the ceramic particles were found inside the cavities indicates that some particles were broken and pulled out from the surface. This suggests an abrasive wear mechanism, which is essentially due to exposure of hard ceramic particles on the worn surface and loose fragments between two surfaces [30]. As the ceramic particles resist the delamination process, the wear resistance is more in the case of composites alloy [31].

\section{Conclusions}

Based on the experimental observations made in the present research, the following conclusions have been drawn.

- A16061 alloy matrix composites have been successfully developed with fairly uniform dispersion of beryl particles.

- Tensile strength of Al6061/10\%. Wt. of beryl composites shows $15.38 \%$ more when compared to Al6061 base alloy.

- The sliding wear weight loss of the Al6061/beryl composites shows an inverse relationship with the quantity of addition of beryl particles.

- Specific wear rate was observed to be approximately $8.9 \%$ less when compared to base alloy.

\section{Acknowledgements}

One of the authors (Mr. H. N. Reddappa) acknowledges Vokkaligara Sangha, Bangalore for financial support. Also, the authors sincerely thank the Management of Bangalore Institute of Technology and BMS College of Engineering with which the authors are associated presently for their support and encouragement for this work.

\section{REFERENCES}

[1] K. R. Suresh, H. B. Niranjan, P. Martin Jabraj and M. P. Chowdaiah, "Tensile and Wear Properties of Aluminium Composites," Wear, Vol. 255, No. 1-6, 2003. pp. 638-642. doi:10.1016/S0043-1648(03)00292-8

[2] D. M. Taylor, "Metals Hand Book," ASM, Materials Park, 1982, pp. 859-863.

[3] P. K. Rohatgi, "Cast Metal Matrix Composites Metal Hand Book," 9th Edition, ASM International, Materials 
Park, 1988.

[4] K. G. Sathyanarayana, R. M. Pillai, B. C. Pai, M. Kestursatya, P. K. Rohatgi and J. K. Kim, "Developments in Cast Metal Matrix Composites over Last Three and Half Decades," In: E. S. Dwarakadas and C. G. Krishnadas Nair, Eds., Proceedings of the Third International Conference on Advances in Composites, Bangalore, 2002, pp. 753-763.

[5] C. S. Ramesh, "Processing and Characterization of Metal Matrix Composites," Proceedings of the National Seminar on Recent Trends in Liquid Crystals, Polymer, and Composite Materials, Ramanagaram, 2003, pp. 10-13.

[6] F. M. Hosking, F. Folgar Poritillo, R. Wunderlein and R. Mehrabion, "Composite of Al Alloys Fabrication and Wear Behaviour," Journal of Materials Science, Vol. 17, No. 2, 1982, pp. 477-498. doi:10.1007/BF00591483

[7] A. Wang and H. J. Rack, "Transition Wear Behavior of SiC-Particulate and SiC-Whisker-Reinforced 7091 Al Metal Matrix Composite," Materials Science and Engineering: A, Vol. 147, No. 2, 1991, pp. 211-224. doi:10.1016/0921-5093(91)90848-H

[8] A. Wang and I. M. Hutchings, "Wear of Alumina Fiber: Aluminum Metal Matrix Composite by Two Body Abrasion," Materials Science and Technology, Vol. 5, No. 1, 1989, pp. 71-76. doi:10.1179/026708389790337503

[9] C. S. Ramesh, A. R. Anwar Khan and A. Ramachandra, "Heat Treatment of Al6061-10 wt\% SiC Composites," In: A. F. M. Anwarul Haque, M. Ahmed, A. N. Mustafizul Karim, N. R. Dhar and S. Begum, Eds., Proceedings of the International Conference on Manufacturing, ICM Dhaka, 2002, pp. 21-28.

[10] C. S. Ramesh, S. K. Seshadri and K. J. L. Iyer, "A Survey on Aspects of Wear of Metals," Indian Journal of Technology, Vol. 29, 1991, pp. 179-185.

[11] C. S. Ramesh, R. Noor Ahmed and M. Safiualla, "Strength and Wear Properties of Cast Copper-TiO ${ }_{2}$-Boric Acid Hybrid Composites," In: V. C. Venkatesh and S. Mirdha, Eds., Proceedings of the International Conference ICMAT, Kaula Lumpur, 2004, pp. 836-839.

[12] C. S. Ramesh and R. Noor Ahmed, "A Comparative Study on Cast Copper-SiC-Gr and Copper-TiO ${ }_{2}$-Boric Acid Hybrid Composites," In: A. Kori, Ed., Proceedings of the National Conference AMTP, Bagalkot, 2004, pp. 836-839.

[13] A. Shashishankar, M. Krishna and C. S. Chandrasekhara Murthy, "A Study on Sliding Behaviour of Flyash Reinforced Aluminium 7075 Alloy Composites," In: E. S. Dwarakadas and C. G. Krishnadas Nair, Eds., Proceedings of the Third International Conference on Advances in Composites, Bangalore, 2002, pp. 583-589.

[14] W. F. Smith, "Structure and Properties of Engineering Alloys," 2nd Edition, McGraw-Hill, New York, 1993.

[15] L. G. Berry and B. Mason, "Mineralogy," N.H. Freeman \& Co., New York, 1959.

[16] N. A. Deer and J. Zussman, "Rock Forming Minerals," Longmans Pub. Ltd., London, 2003.

[17] A. B. Gurcan and T. N. Baker, "Wear," Elsevier Sequoia,
Lausanne, 1995, pp. 185-191. doi:10.1016/0043-1648(95)06639-X

[18] R. Higgins, "Engineering Metallurgy," Krieger Publishing Company, Melbourne, 1983, p. 181.

[19] R. A. Flinn and P. D. Trojan, "Engineering Materials and Their Applications," 4th Edition, Jaico Pub. House, Bombay, 1993, p. 650 .

[20] G. E Deiter, "Mechanical Metallurgy," 2nd Edition, McGraw-Hill, Kongakusha, 1981, p. 221.

[21] R. J. Arenault and R. M. Fischer, "Microstructure of Fiber and Particulate $\mathrm{SiC}$ in $6061 \mathrm{Al}$ Composites," Scripta Metallurgica, Vol. 17, No. 1, 1983, pp. 67-71. doi:10.1016/0036-9748(83)90072-8

[22] R. J. Arenault, "The Strengthening of Aluminum Alloy 6061 by Fiber and Platelet Silicon Carbide," Materials Science and Engineering, Vol. 64, No. 2, 1984, pp. 171181. doi:10.1016/0025-5416(84)90101-0

[23] M. K. Surappa, "Fabrication and Characterization of AlCeramic Particle Composites," Ph.D. Thesis, Indian Institute of Science (IISc.), Bangalore, 1979.

[24] J. Guralnd, "Composite Materials," Academic Press, Cambridge, 1974.

[25] D. A. Koss and S. M. Coply, "Thermally Induced Residual Stress in Eutectic Composites," Metallurgical and Materials Transactions A, Vol. 2, No. 6, 1971, pp. 1557 1560.

[26] W. J. Clegg, "A Stress Analysis of the Tensile Deformation of Metal Matrix Composites," Acta Metallurgica et Materialia, Vol. 36, No. 8, 1988, pp. 2141-2149. doi:10.1016/0001-6160(88)90315-X

[27] M. Taya, K. E. Lulay and D. L. Lloyd, "Strengthening of a Particulate Metal Matrix Composite by Quenching," Acta Metallurgica et Materialia, Vol. 39, No. 1, 1991, pp. 73-87. doi:10.1016/0956-7151(91)90329-Y

[28] D. L. McDanieal, “Analysis of Stress-Strain, Fracture and Ductility Behavior of Al MMCs Containing Discontinuous Silicon Carbide Reinforcement," Metallurgical and Materials Transactions A, Vol. 16, No. 6, 1985, pp. 11051113. doi:10.1007/BF02811679

[29] S. Basavarajappa, G. Chandramohan, K. Mukund, M. Ashwin and M. Prabu, "Dry Sliding Wear Behavior of Al 2219/SiCp-Gr Hybrid Metal Matrix Composites," Journal of Materials Engineering and Performance, Vol. 15, No. 16, 2006, pp. 668-674. doi:10.1361/105994906X150803

[30] G. B. Veeresh Kumar, C. S. P. Rao and N. Selvaraj, "Studies on Mechanical and Dry Sliding Wear of Al6061-SiC Composites," Composites Part B: Engineering, Vol. 43, No. 3, 2011, pp. 1185-1191. doi:10.1016/j.compositesb.2011.08.046

[31] F. Tang, X. L. Wu, S. R. Ge, J. C. Ye, H. Zhu, M. Hagiwara and J. M. Schoenung, "Dry Sliding Friction and Wear Properties of B4C Particulate-Reinforced Al-5083 Matrix Composites," Wear, Vol. 264, No. 7-8, 2008, pp. 555-561. doi:10.1016/j.wear.2007.04.006 